\title{
Grain-size evolution of polar firn: a new empirical grain growth parameterization based on X-ray microcomputer tomography measurements
}

\author{
Stefanie LINOW, ${ }^{1}$ Maria W. HÖRHOLD, ${ }^{2}$ Johannes FREITAG ${ }^{1}$ \\ ${ }^{1}$ Alfred Wegener Institute for Polar and Marine Research, Bremerhaven, Germany \\ E-mail: stefanie.linow@awi.de \\ ${ }^{2}$ University of Bremen, Bremen, Germany
}

\begin{abstract}
Firn microstructure properties from six different sites in Greenland and Antarctica are investigated by means of $\mathrm{X}$-ray microcomputer tomography. The optical effective radius is calculated from the specific surface area (SSA) and used as a measure of grain size. It is shown that the recently introduced spherical approximation of firn grains using the effective radius $\boldsymbol{R}_{\text {eff }}$ is representative of grain size in the microwave frequency region. The measured profiles show the well-known increase of grain size with depth at all sites, where the increase is largest at near-surface depths. A large variability in grain size on the decimeter-to-centimeter scale as a result of different grain properties of single layers is superimposed on the overall trend at each site. A simple empirical parameterization of grain-size evolution is developed which allows the rapid grain growth in the uppermost layers of the firn to be predicted. The growth is driven by strong seasonal and diurnal temperature gradients. The model can be used to simulate grain-size profiles required by models of firn/microwave interaction (e.g. for retrieval of accumulation rates from satellite microwave sensors) in a more realistic fashion.
\end{abstract}

\section{INTRODUCTION}

Microwave remote sensing has become an important tool to observe changes in mass balance of the polar ice sheets (Flach and others, 2005; Lacroix and others, 2008). While representative point measurements on the ground over large areas are often lacking, remote-sensing methods can in principle be used for spatial upscaling (Domine and others, 2008). However, for analysis of the resulting images it is necessary to consider microwave/firn interactions in the upper layers of the snowpack, as penetration depths of microwaves into the firn range from $\mathrm{cm}$ to $\sim 100 \mathrm{~m}$ (Legrésy and Rémy, 1998). For this application, knowledge of the grain size plays a crucial role, since the backscattering behaviour (for active microwave imaging) as well as the emissivity (for passive microwave imaging) is strongly influenced by grain size (e.g. Rott and others, 1993; West, 1994). For optical remote-sensing techniques, the surface grain size is equally important, since it influences the albedo (Aoki and others, 2000). However, using microwave sensors, the grain-size evolution with depth needs to be considered. Thus, in order to interpret microwave images, the grainsize profile as well as the interaction of microwaves with the grains has to be considered (Brucker and others, 2010). Therefore, it is important to validate grain-size parameters used in remote-sensing applications with ground truth.

Microstructure measurements of the upper firn column of the polar ice sheets are difficult and time-consuming to obtain. Grain-size measurements were conducted at single locations in Antarctica and Greenland by, for example, Gow (1969), Alley and others (1982), Gay and others (2002), Freitag and others (2004), Gow and others (2004) and Courville and others (2007). Few studies exist that compare firn microstructure at different sites (e.g. Taylor, 1971; Nishimura and Maeno, 1985; Shiraiwa and others, 1996; Gay and others, 2002). The difficulties in comparing the published data lie in the application of different methods of grain-size definition and determination, and the different spatial resolution of the datasets. Another problem is that measurements were taken at different times of the year. Since snow grains show a large variety in their shapes, a number of different parameters are in use to quantify the grain size. Recently, the effective radius determined from the specific surface area (SSA) was introduced as a suitable parameter for grain-size quantification, as it takes the interaction at the air/ice interface in chemical or physical processes into account (Domine and others, 2008). Several alpine snow measurements and experiments were conducted using the effective radius, the SSA and other physical properties as comparable parameters for different snow types and their change with time (Flin and others, 2004; Schneebeli and Sokratov, 2004; Kaempfer and Schneebeli, 2007). SSA profiles of the upper meter of the firn column were measured in Antarctica by Gallet and others $(2009,2011)$. To date, the most comprehensive overview of available snow properties is given by Domine and others (2008) for alpine snow. An extensive study conducted by Gay and others (2002) for Antarctic snow uses a different grain-size definition, and sampling depths are restricted to the upper $2 \mathrm{~m}$ of the snowpack. A comparable and systematic study of polar snow and firn, investigating the grain size in terms of evolution with depth and time under different local climate conditions, does not yet exist. Computer tomography has established itself as a valuable tool for examining snow and firn microstructure (Schneebeli and Sokratov, 2004; Kaempfer and Schneebeli, 2007), being well suited to realistically reproducing snow parameters such as density (Freitag and others, 2004). Using this method, we analyze a set of grain-size measurements from six climatologically heterogeneous sites on the polar ice sheets. We use the effective radius obtained from the SSA to investigate the grain-size evolution as a function of depth and time. From the new dataset, a simple grain growth model is developed which is able to capture the rapid grain growth 

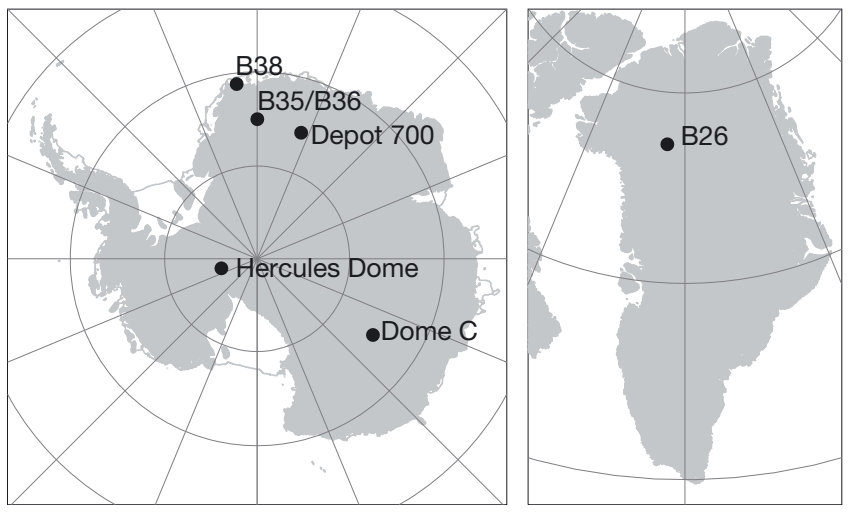

Fig. 1. The location of the firn cores.

in the uppermost firn layers for a wide range of polar climate conditions. This model can be used to verify and improve grain-size modeling for remote-sensing applications.

\section{METHODS}

\subsection{Firn-core locations}

Six surface firn cores, one from Greenland and five from Antarctica, are analyzed. They cover a broad range of annual mean surface temperatures, accumulation rates, elevations and distances to the coast (Fig. 1; Table 1). Annual mean temperatures and accumulation rates are obtained from published data, except for the Antarctic site Depot 700 (DP7; Table 1). The B26 firn core shows intermediate annual surface temperature conditions on the Greenland plateau and medium accumulation rates. In our dataset from Antarctica the location of the FireTrack (FT) firn core from Dome $\mathrm{C}$ has the lowest temperatures and accumulation rates. Unfortunately, the available data start from $6.6 \mathrm{~m}$ below the surface to larger depths. The DP7 firn core shows a similar annual mean temperature (estimated from Moderate Resolution Imaging Spectroradiometer (MODIS) surface temperature data (LP DAAC, 2009)), and a slightly higher accumulation rate estimated from interpolation of accumulation rates of nearby sites (Isaksson and others, 1999). From Kohnen station (EDML drilling site) two firn cores, B35 and B36, are available, representative of medium-range accumulation rates and temperatures on the Antarctic plateau. While the Hercules Dome firn core represents medium to low temperatures and medium accumulation rates, the B38 firn core from the coastal area shows a remarkably high accumulation rate and a higher mean temperature. With a temperature range between $-18^{\circ} \mathrm{C}$ and $-54.5^{\circ} \mathrm{C}$ and accumulation rates between 0.025 and $1.25 \mathrm{~m}$ w.e., our dataset covers a large fraction of climate conditions of polar ice sheets.

\subsection{Density measurements}

Density was measured with a vertical resolution of $1 \mathrm{~mm}$ using a non-destructive logging system including a Löffel densimeter (Wilhelms, 1996). The radiation source was ${ }^{137} \mathrm{Cs}$. Using the measured gamma-ray signal intensity, I, in relation to the signal's intensity in air, $I(0)$, the mass absorption coefficient $\mu_{\text {ice }}=0.085645 \pm 0.01 \mathrm{~m}^{2} \mathrm{~kg}^{-1}$ (Wilhelms, 1996, 2000) and the diameter $d$ of the medium, the density can be calculated. Details are given by Wilhelms (1996, 2000) and Hörhold and others (2011). All measurements were conducted at temperatures of $-20^{\circ} \mathrm{C}$ in the cold laboratory of the Alfred Wegener Institute (AWI), Bremerhaven, Germany. High-resolution density measurements were conducted for all but the Hercules Dome firn core. For each core, an approximate age profile was calculated using the water equivalent depth derived from the density measurements and the known accumulation rate.

\subsection{Computer tomography and image analysis}

Microstructure images were generated by microcomputer tomography (CT) using a SkyScan CT1072 operating at $80 \mathrm{kV}$ for B38 and a CT1074 operating at $40 \mathrm{kV}$ for all the other firn cores. Cylindric snow samples of $2.5 \mathrm{~cm}$ length and $2 \mathrm{~cm}$ in diameter (1 $\mathrm{cm}$ for B38) were placed on a table in front of an X-ray source. The table was rotated in steps of $0.9^{\circ}$, and each time a shadow image was taken. The resulting set of images was converted to a stack of horizontal grayvalue images at $15.73 \mu \mathrm{m}$ resolution (B38) and $40 \mu \mathrm{m}$ (all other cores) using a back-projection procedure. For cores B35, B36, B38 and DP7 the uppermost 1-2 m were sampled continuously. Below, 16 samples were taken on a length of $40 \mathrm{~cm}$ for each $1 \mathrm{~m}$ interval (Fig. 2). B26 is sampled every meter from the surface. The Hercules Dome dataset contains

Table 1. Firn-core locations and local climate conditions

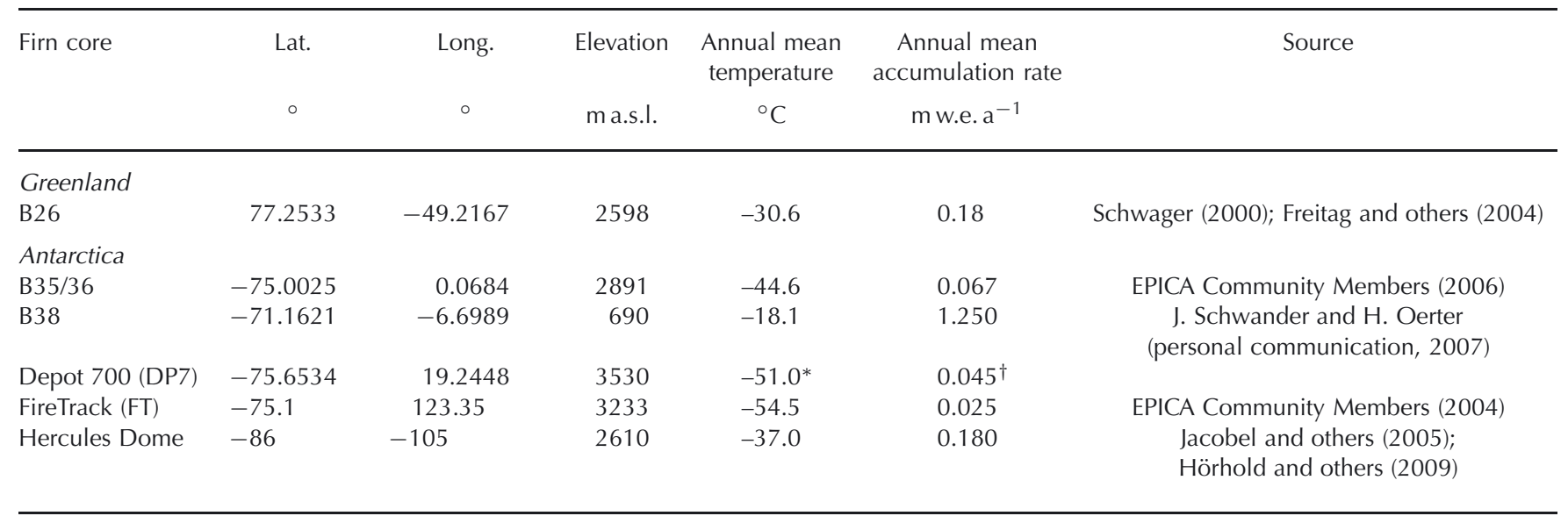

\footnotetext{
*Estimated from MODIS surface temperature data.

$\dagger$ Estimated from interpolation of accumulation rates of nearby sites (Isaksson and others, 1999).
} 


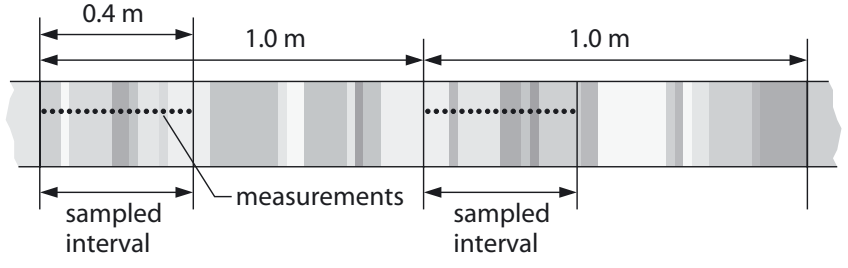

Fig. 2. Firn-core sampling schematic

discontinuous samples with non-equal steps throughout the firn core. The lowermost meter of both B38 and B26 was sampled continuously again. The number of samples in each interval varies from 16 to $>20$ (Table 2).

For image analysis the software MAVI (Modular Algorithms for Volume Images) developed by the Fraunhofer Institute for Mathematics, was used (Armbrecht and Sych, 2005). The input data consist of an image stack comprising at least 400 images. From each measured sample a cube of $400 \times 400 \times 400$ voxels $\left(6.3 \times 6.3 \times 6.3 \mathrm{~mm}^{3}\right.$ for B38, and $16 \times 16 \times 16 \mathrm{~mm}^{3}$ for the other cores) was extracted. This size is sufficiently large to be a representative volume for the firn properties considered (Coléou and others, 2001; Kaempfer and Schneebeli, 2007). The datasets were smoothed using a $3 \times 3 \times 3$ median filter. Next, two Gaussian distribution functions were fitted to the gray-value distribution of three images of each stack to determine the threshold value for the segmentation of pore and ice phase. The arithmetic mean of the maximum value of each of the Gaussian distributions determined over three images was used as the threshold gray value for segmentation. Subsequently, an object filter was applied to remove noise, i.e. voxels adding $<1 \%$ to the ice or pore phase. All microstructure parameters obtained by MAVI represent the volume structure of each firn sample rather than, for example, single grains.

Porosity was calculated as the relation between pore fraction and total volume of the sample. Density can be computed from the ice fraction times the density of ice $\left(\rho_{\text {ice }}=0.917 \mathrm{~g} \mathrm{~cm}^{-3}\right)$. The chord length $/$ is defined as the average particle or pore extent in the direction of the sample cube's axes. The SSA represents the ice/air interface per unit mass:

$$
\mathrm{SSA}=\frac{S_{\mathrm{d}}}{\rho}
$$

The SSA is given in $\mathrm{cm}^{2} \mathrm{~g}^{-1}, S_{\mathrm{d}}$ denotes the surface density, i.e. the ratio of the total surface to the total volume of the sample, and $\rho$ is the density of the sample (Domine and others, 2008). The so-called effective radius $R_{\text {eff }}$ can be defined as the radius of equivalent-sized spheres with the same SSA. The relation between SSA and $R_{\text {eff }}$ is

$$
\mathrm{SSA}=\frac{3}{R_{\text {eff }} \rho_{\text {ice }}}
$$

Here it is assumed that the ice phase of the snow and firn can be represented by spheres with a radius $r_{\text {sphere, }}$ such that $r_{\text {sphere }}=R_{\text {eff }}$. To validate this assumption, we used the measured chord length $/$ to calculate the equivalent radius of a sphere:

$$
r_{\text {sphere }}=\frac{4}{3} l_{\text {sphere }}
$$

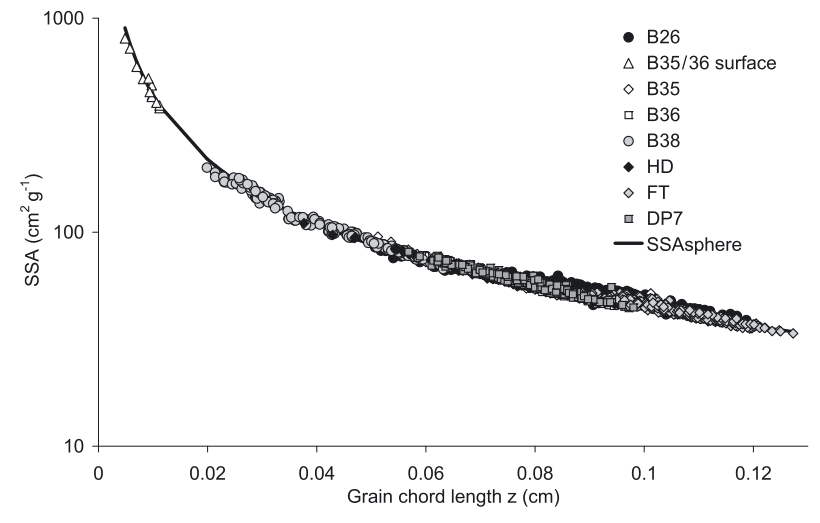

Fig. 3. The SSA obtained from measured surface and density, with the measured chord length of the different sites. The black line is the $\mathrm{SSA}_{\text {sphere, }}$ calculated from the measured chord length under the assumption of equivalent spheres (Eqn (4)). Note the logarithmic scale of the SSA axis.

The $\mathrm{SSA}_{\text {sphere }}$ is calculated by substituting the $R_{\text {eff }}$ in Eqn (2) with Eqn (3):

$$
\mathrm{SSA}_{\text {sphere }} \sim \frac{9}{4 I_{\text {sphere }} \rho}
$$

It reproduces the measured values well, especially given that SSA and chord length are obtained independently (Fig. 3). This supports the assumption that firn microstructure can be realistically represented by spheres with an effective radius $R_{\text {eff }}$ obtained from SSA. Accordingly, in the following we denote grain size by $R_{\text {eff }}$.

\section{MEASUREMENT RESULTS}

\subsection{Density}

The density of all firn cores except HD was measured using the method described in Section 2.2. For the HD core the density was deduced from the CT-image analysis as described in Section 2.3. The density profiles (smoothed by a running mean of $20 \mathrm{~mm}$ ) of the firn cores show large fluctuations due to the firn layering (Fig. 4) and differ in the increase of density with depth. B38 shows the highest density, followed by Hercules Dome. B26 starts with lower density, but its density gradient is larger than those of B36 and DP7. FT shows the lowest density.

Table 2. Depth interval sampled, approximate age interval covered by the samples and number of samples at each core site

\begin{tabular}{lccc}
\hline Name & Depth interval & Approximate firn age & $\begin{array}{c}\text { Number of } \\
\text { samples }\end{array}$ \\
& $\mathrm{m}$ & years & \\
\hline B26 & $0.012-7.3$ & $0.025-16.18$ & 154 \\
B35/36 & $0.29-10.94$ & $1.79-71.26$ & $114 / 121 / 12$ \\
B38 & $0.0325-10.96$ & $0.157-4.4$ & 180 \\
DP7 & $0.05-11.978$ & $0.37-112.27$ & 369 \\
FT & $6.6125-20.36$ & $110.825-367.912$ & 374 \\
HD & $0.076-15.1$ & - & 228 \\
\hline
\end{tabular}




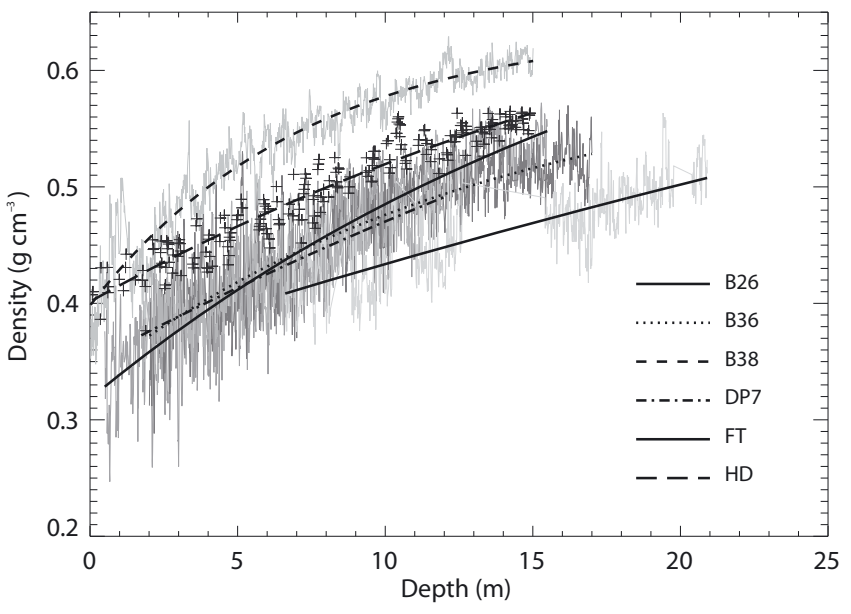

Fig. 4. Density profiles of the measured firn cores.

\subsection{SSA and grain size}

The smallest grain sizes are observed at B38, while DP7 and B26 show the largest grain sizes. At greater depths, FT has the largest grain sizes (Fig. 5a). The SSA decreases rapidly in the uppermost meters. B38 shows the highest values at the surface, and DP7 and B26 the lowest (Fig. 5b) relative to each other. At greater depths, FT shows the lowest SSA values. For all sites we find a rapid decrease in SSA in the upper few meters (Fig. 5b). From visual inspection it seems that the strongest increase in grain size with depth in the uppermost meter occurs at B26 and DP7.

\section{THE GRAIN GROWTH MODEL}

\subsection{Parameterization of grain growth}

Various methods for modeling grain growth processes have been described in the literature. Colbeck (1983), Jordan (1991) and Baunach and others (2001) modeled temperature gradient growth as a process driven by the saturation vaporpressure gradient. In this case, grains grow only when there is a temperature gradient present within the snowpack, neglecting equi-temperature growth processes. Flanner and Zender (2006), among others, have created complex threedimensional models of firn metamorphism that consider physical processes of grain growth in great detail but require substantial computation time. For a number of applications, though, it is desirable to use a simple, fast and empirical one-dimensional approach to model firn properties. Maeno and Ebinuma (1983) found that snow grain growth can be described as a pressure sintering process, and there are many examples in the literature where the Arrhenius equation is used to model equi-temperature grain growth as a function of depth (e.g. Alley and others, 1982; Gow and others, 2004; Flach and others, 2005). However, due to a lack of comparable grain-size data, it has been difficult to assess the accuracy of grain-size profiles simulated using the methods mentioned above. In our approach, grain-size evolution is parameterized using a simple steady-state particle growth model. Snow accumulation has been found to vary on the order of tens of $\mathrm{km}$ (Eisen, 2008). The sensor footprints of passive microwave radiometers vary between 10 and a few tens of $\mathrm{km}$. In such cases, short-distance variations of the firn layer properties cannot be resolved by remote-sensing measurements. In addition, very few field data are available
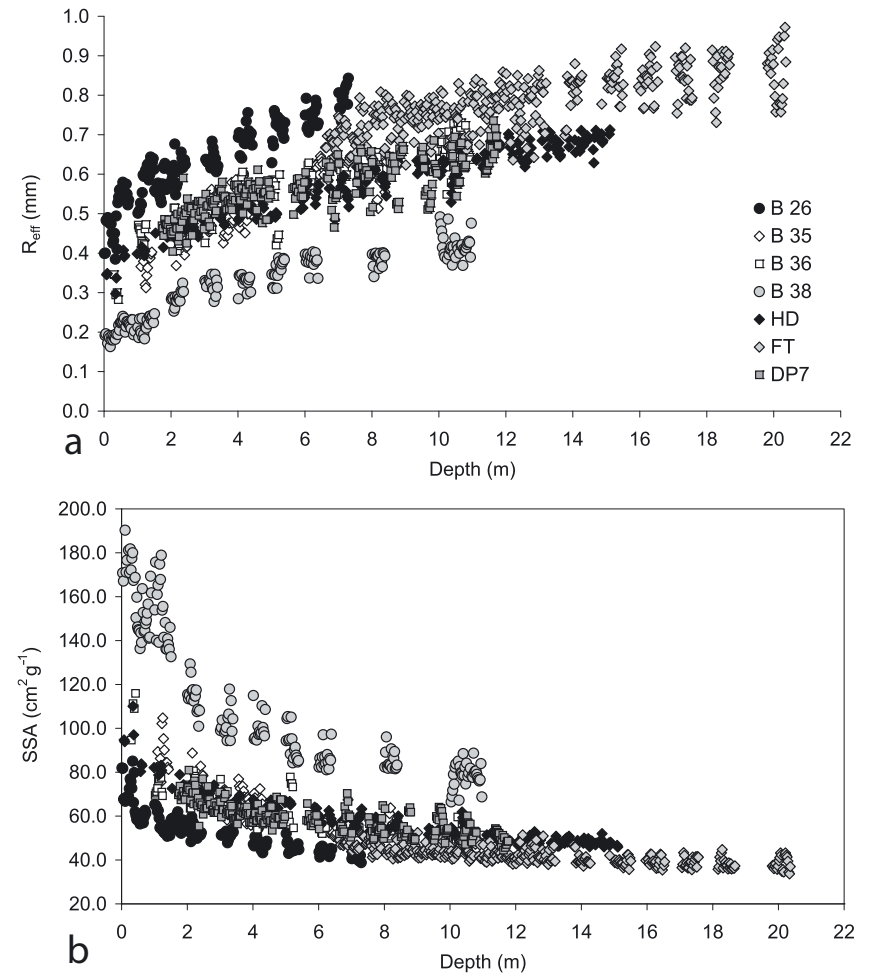

Fig. 5. Variation of the SSA and of $R_{\text {eff }}$ with depth at the different sites.

that are acquired on a spatially dense grid to account for local lateral variations of firn layer properties. For remote-sensing applications we assume a homogeneous stratigraphy on horizontal scales of the sensor footprint size and approximate vertical variations of firn properties by mean profiles.

We initialize our firn profile by distinct horizontal layers corresponding to half-year intervals. Firn properties change from layer to layer but remain constant within each layer. The radius $r(t)$ of a particle is then determined from an initial radius $r_{0}$ and the growth rate $K$ as a function of time $t$

$$
r^{2}(t)=K t+r_{0}^{2}
$$

The Arrhenius equation is used to calculate the growth rate $K$, which is a function of rate constant $K_{0}$, activation energy $E$, gas constant $R$ and absolute temperature $T$ :

$$
K=K_{0} \exp (-E / R T)
$$

The above parameterization assumes linear particle growth under isothermal conditions. In the literature, values of $E$ vary between $47.0 \times 10^{3} \mathrm{~J} \mathrm{~mol}^{-1}$ (Gow, 1969) and $42.4 \times 10^{3} \mathrm{~J} \mathrm{~mol}^{-1}$ (Paterson, 1994). Flach and others (2005) give a $K_{0}$ value of $6.75 \times 10^{7} \mathrm{~mm}^{2} \mathrm{a}^{-1}$, while the $K_{0}$ given by Arthern and others (2010) is on the order of $4.1 \times 10^{6} \mathrm{~mm}^{2} \mathrm{a}^{-1}$. Growth rates calculated from the above range of parameters vary considerably. Budd and Jacka (1989) assumed $E$ and $K_{0}$ are temperature-dependent, and Jacka and Li (1994) supplied parameters to empirically fit activation energy $E$ and growth rate $K$ to temperature. The initial value $r_{0}$ is usually fixed at an arbitrary value, due to a lack of reference values obtained from the field. We have chosen to empirically fit $K$ to temperature and to develop a parameterization for the initial grain size. 


\subsection{Firn temperature}

From the measured grain-size profiles we aim to find a parameterization of grain growth as a function of mean annual surface temperature $T$, maximum temperature amplitude at the surface $\Delta T$ and mean accumulation rate $A$. To determine mean grain size dependent on depth in the firn, the measured effective radii are averaged over the measurement intervals of $\sim 40 \mathrm{~cm}$ (see Section 2.3; Fig. 2). Firn age $t(z)$ and depth $z$ are related by the velocity $v(z)=$ $A \rho_{\text {ice }} / \rho(z)$ at which a snow layer is buried below the surface (Munk and others, 2003):

$$
t(z)=\int_{0}^{z} \frac{d z^{\prime}}{v(z)}
$$

Temperature propagation into the snowpack $T(z)$ is modeled as an exponentially decaying oscillation as described by Paterson (1994), depending on annual mean temperature $\bar{T}$, amplitude of the seasonal temperature signal at the surface $\Delta T$, thermal diffusivity of snow $k$, and frequency $\omega=2 \pi$ and phase $\varphi=0.279$ of the seasonal signal. The growth rate depends on the temperature gradient and the absolute temperature. Based on our observations, we assume that the growth rate at the maximum absolute temperature dominates the particle growth processes over the seasonal cycle. For this reason we fixed the phase value at the day when the maximum of the seasonal temperature is reached. Since the focus of microwave remote-sensing applications is on timescales of decades, and the measured signal is also influenced by deeper firn layers not affected by recent surface processes, we neglect near-surface temperature variations on shorter than seasonal timescales.

$$
T(z)=\bar{T}+\Delta T \exp (-z \sqrt{\omega / 2 k}) \sin (\omega \varphi-z \sqrt{\omega / 2 k})
$$

Annual mean temperature $\bar{T}$ and amplitude $\Delta T$ can be obtained from the MODIS Land Surface Temperature data product (LP DAAC, 2009). Thermal diffusivity can be calculated from thermal conductivity. The latter depends on temperature and crystal structure and is not easy to parameterize (Domine and others, 2008). Therefore, density is used as a proxy for grain characteristics. Here we apply the empirical approach developed by Sturm and others (1997).

\subsection{Growth rate}

Input data for determining the growth rate as a function of measured radius are mean grain-size profiles with corresponding values for temperature $T$, maximum temperature amplitude $\Delta T$ (derived from the temperature profile in Eqn (8)), measured density and firn age. The growth rate $K$, which is defined as the change of grain size with time, is evaluated numerically for every depth interval. We compared growth rates determined from our dataset with values published by Paterson (1994), and found our values in good accordance (Fig. 6), albeit systematically larger. A possible explanation for this effect lies in the fact that the Paterson values were determined at greater depths, closer to the firn/ice transition. Additionally, different methods were used to determine grain size, and as a result the above comparison can only be approximate. The temperaturedependent activation energy $E$ and rate constant $K_{0}$ are difficult to fit numerically to parameters obtained rom measurements, since they are very sensitive to noise in the data. For this reason, we chose to fit the growth rate $K$ directly to $T$, and determine coefficients for Eqn (9). From

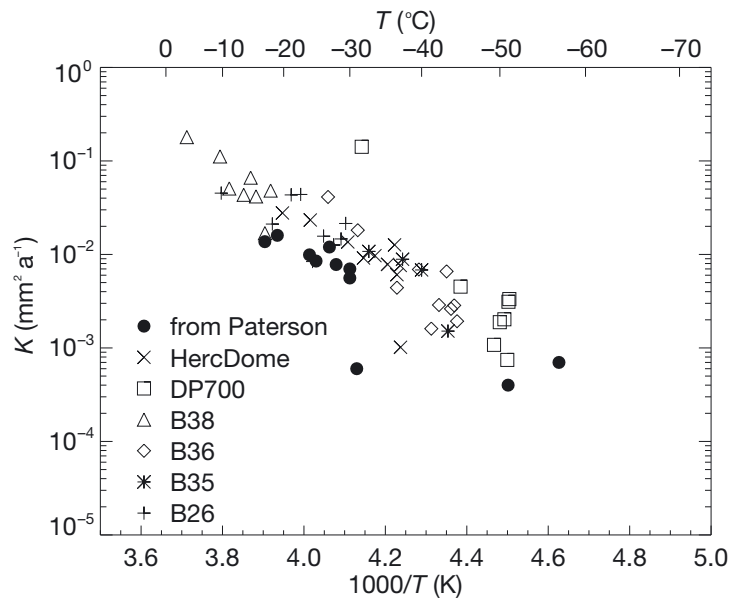

Fig. 6. Growth rates derived from profile data and from Paterson (1994).

the available data, no correlation between $K$ and $A$ can be inferred, therefore $K$ is modeled to depend solely on temperature:

$$
K(T)=a_{0} \exp \left\{a_{1}\left[1000 /(\bar{T}+\Delta T)+a_{2}\right]\right\}
$$

We obtained the following parameter set to estimate the temperature-dependent growth rate:

$$
\begin{aligned}
& a_{0}=0.165 \mathrm{~mm}^{2} \mathrm{a}^{-1} \\
& a_{1}=-5.218 \mathrm{~K} \\
& a_{2}=-3.712 \mathrm{~K}^{-1}
\end{aligned}
$$

\subsection{Surface grain size}

For remote-sensing applications, it is convenient to define the initial grain size $r_{0}$ as an average radius over a subsurface layer of predefined thickness, which differs from the grain size at the time of snow deposition and is influenced by the metamorphism processes that took place between the time when the lowest part of the subsurface layer was deposited and the time of the remote-sensing measurements. To quantify the temperature and accumulation dependency of the surface grain size, initial radii $r_{0}$ and their standard deviation $\sigma_{r_{0}}$ were estimated from the measured grain sizes of the upper $30 \mathrm{~cm}$ interval of each measured individual profile. This was done for all available grain-size profiles except the FT profile since that starts at a depth of $6 \mathrm{~m}$.

A multiple linear regression applied to the Table 3 data yields the following relationship between initial grain radius $r_{0}$, mean annual temperature $\bar{T}\left({ }^{\circ} \mathrm{C}\right)$ and accumulation rate $A$ (m w.e. $\left.\mathrm{a}^{-1}\right)$.

$$
r_{0}(\bar{T}, A)=b_{0}+b_{1} \bar{T}+b_{2} A
$$

with

$$
\begin{aligned}
& b_{0}=0.781 \pm 0.019 \\
& b_{1}=0.0085 \pm 0.002 \\
& b_{2}=-0.279 \pm 0.055
\end{aligned}
$$

In order to test the accuracy of our fit, we compared initial radii determined from Eqn (11) with measured values. It can be seen that our multiple regression approach reproduces the measured values with sufficient accuracy (Fig. 7). The grain size of the near-surface layer $r_{0}$ seems to depend on temperature and accumulation rate. Larger water-vapor transport and thus faster grain growth are linked 


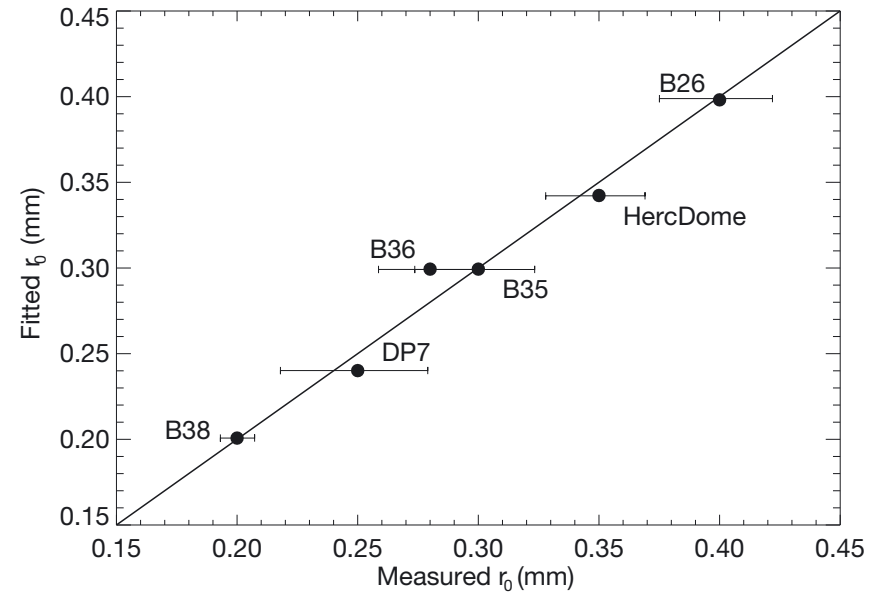

Fig. 7. Correlation between simulated and measured surface grain sizes.

to higher temperatures (Domine and others, 2008). Higher accumulation reduces the time the snow grains are subject to a strong temperature gradient and slows the grain growth process.

\subsection{Modeled grain-size profiles}

Figure 8 shows that the rapid grain growth in the upper layers influenced by a strong temperature gradient is represented more realistically by the new approach. Our model overestimates grain growth for B38, a site with an extremely high accumulation rate of $1.25 \mathrm{mw}^{\mathrm{e} . \mathrm{a}^{-1}}$ and a comparably high mean annual surface temperature of $-18^{\circ} \mathrm{C}$. For DP7, the extreme particle growth is caused by a very low accumulation rate of $\sim 0.045 \mathrm{mw}$.e. $\mathrm{a}^{-1}$ and, in consequence, the long exposure time of snow layers to a large temperature gradient. This effect is underestimated in our model. For intermediate polar climate conditions, the simulated grain-size profiles closely fit the measurements. Figure 8 compares model results with measurements and grain-size parameterizations by Paterson (1994) and Zwally and Li (2002). Since start values for the grain growth were not given in both examples, we calculated initial radii $r_{0}$ from Eqn (11) for better comparison. Both approaches also model grain sizes using Eqns (5) and (6), albeit with different values for growth rate and activation energy. The parameters given by Paterson (1994) are optimized to reflect particle growth under isothermal conditions (see Fig. 6; Section 4.1) and hence does not represent conditions found in the uppermost firn layers in the presence of a strong temperature gradient. The work by Zwally and Li (2002) results in a temperature-dependent parameter set for growth rate and activation energy and is based on data from field studies and laboratory experiments Jacka and Li (1994) obtained under isothermal conditions. Hence, results from this parameter set are expected to deviate from observations of particle evolution in near-surface layers.

The competing impact of temperature and accumulation rate leads to overestimation of the B38 samples and underestimation of the DP7 and FT samples. This indicates a lower sensitivity of the model parameters to extreme conditions, but the overall agreement of data and model results is good. Possible sources of error in the development of the parameterization stem from uncertainties in accumulation rates and temperatures, which are difficult to quantify. Even
Table 3. Initial radii, radius standard deviation, temperatures, accumulation rates and number of samples $N$

\begin{tabular}{lccccc}
\hline Firn core & $r_{0}$ & $\sigma_{r_{0}}$ & $\bar{T}$ & $A$ & $N$ \\
& $\mathrm{~mm}$ & $\mathrm{~mm}$ & ${ }^{o} \mathrm{C}$ & $\mathrm{m} w . e . ~^{-1}$ & \\
\hline B26 & 0.40 & \pm 0.033 & -31.60 & 0.180 & 12 \\
B35 & 0.30 & \pm 0.035 & -44.60 & 0.067 & 12 \\
B36 & 0.28 & \pm 0.028 & -44.60 & 0.067 & 4 \\
B38 & 0.20 & \pm 0.010 & -18.10 & 1.250 & 10 \\
DP7 & 0.25 & \pm 0.043 & -51.00 & 0.045 & 10 \\
Hercules Dome & 0.35 & \pm 0.029 & -37.00 & 0.180 & 3 \\
\hline
\end{tabular}

though the results of the linear regression for the initial radius $r_{0}$ (Fig. 7) seem to be nearly perfect, it is difficult to say whether the parameterization approach remains valid when more datasets are considered. A comparison of modeled grain radii with model results from Flanner and Zender (2006) for temperature gradient growth yields comparable grain sizes.

\section{CONCLUSION}

From computer-tomography measurements we showed that firn grains can be approximated as spheres for remotesensing applications. The use of an effective (or optical) radius can be reproduced by different measurement methods and can be used to parameterize grain size. A simple, empirical parameterization of grain growth processes based on the Arrhenius equation is introduced. It incorporates effects of the strong particle growth in the upper layers of the snowpack caused by thermal gradients as well as equi-temperature growth at depths no longer influenced by the seasonal temperature change. The new model includes a parameter set for estimating the surface grain size as a function of accumulation rate and mean air temperature at the surface. Since the firn cores used to derive our model parameter set do not exceed $\sim 20$ m depth, we cannot predict the accuracy of our model results for greater depths. Therefore we recommend this model for remote-sensing applications for which firn/microwave interactions have to be considered in the upper layers of the snowpack down to 20$30 \mathrm{~m}$. Because microwave radiation is sensitive to particle size, a more accurately simulated firn profile can be used to improve many applications (e.g. the retrieval of snow accumulation rates or an inversion of surface grain sizes from microwave satellite data). Since we used data from six firn cores from Greenland and Antarctica which represent a heterogeneous set of environmental conditions, we can safely assume our model is applicable to many regions of Greenland and Antarctica. In order to further test the validity of our relation for estimating surface grain sizes, more data will be needed.

\section{ACKNOWLEDGEMENTS}

We thank Zoe Courville for providing the Hercules Dome and Depot 700 firn-core material. We also thank Wolfgang Dierking for valuable advice. S. Linow was funded by the German Science Foundation (DFG; SPP-1257: Mass Transport and Mass Distribution in the Earth System). M. Hörhold was funded by DFG grant FR 2527/1-1. 

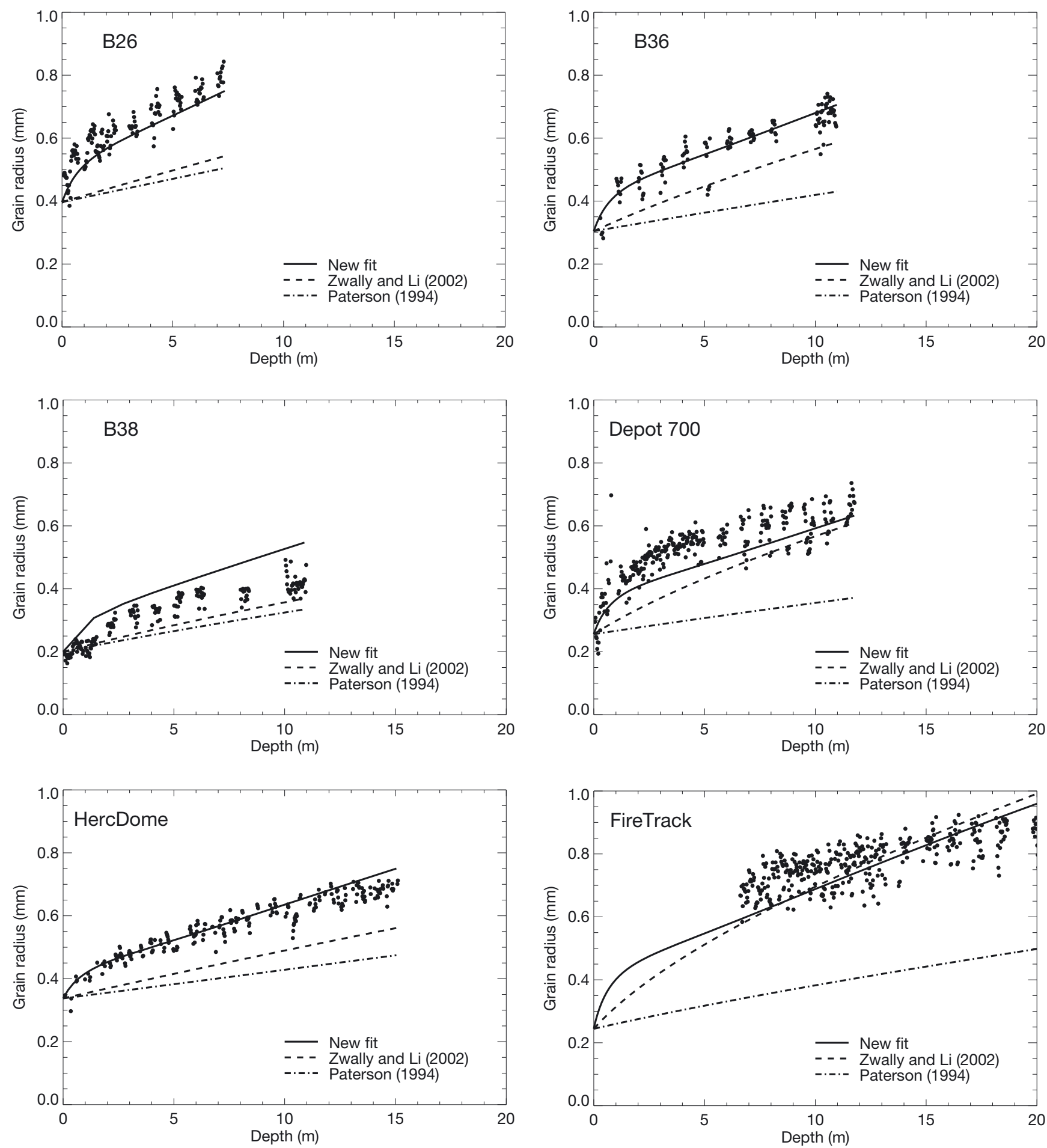

Fig. 8. Modeled grain-size profiles for six polar firn cores

\section{REFERENCES}

Alley RB, Bolzan JF and Whillans IM (1982) Polar firn densification and grain growth. Ann. Glaciol., 3, 7-11

Aoki T, Aoki T, Fukabori M, Hachikubo A, Tachibana $\mathrm{Y}$ and Nishio F (2000) Effects of snow physical parameters on spectral albedo and bi-directional reflectance of snow surface. J. Geophys. Res., 105(D8), 10 219-10 236 (doi: 10.1029/1999JD901122)

Armbrecht J and Sych T (2005) MAVI - Modular algorithms for volume images. Fraunhofer Institut für Techno- und Wirtschaftsmathematik, Kaiserslautern

Arthern RJ, Vaughan DG, Rankin AM, Mulvaney R and Thomas ER (2010) In situ measurements of Antarctic snow compaction

compared with predictions of models. J. Geophys. Res., 115(F3), F03011 (doi: 10.1029/2009JF001306)

Baunach T, Fierz C, Satyawali PK and Schneebeli M (2001) A model for kinetic grain growth. Ann. Glaciol., 32, 1-6 (doi: 10.3189/172756401781819427)

Brucker L, Picard G and Fily M (2010) Snow grain-size profiles deduced from microwave snow emissivities in Antarctica. J. Glaciol., 56(197), 514-526 (doi: 10.3189/ 002214310792447806)

Budd WF and Jacka TH (1989) A review of ice rheology for ice sheet modelling. Cold Reg. Sci. Technol., 16(2), 107-144

Colbeck SC (1983) Theory of metamorphism of dry snow. J. Geophys. Res., 88(C9), 5475-5482 (doi: 10.1029/JC088iC09p05475) 
Coléou C, Lesaffre B, Brzoska JB, Ludwig W and Boller E (2001) Three-dimensional snow images by X-ray microtomography. Ann. Glaciol., 32, 75-81 (doi: 10.3189/172756401781819418)

Courville ZR, Albert MR, Fahnestock MA, Cathles LM and Shuman CA (2007) Impacts of an accumulation hiatus on the physical properties of firn at a low-accumulation polar site. J. Geophys. Res., 112(F2), F02030 (doi: 10.1029/2005JF000429)

Domine F and 7 others (2008) Snow physics as relevant to snow photochemistry. Atmos. Chem. Phys., 8(2), 171-208 (doi: 10.5194/acp-8-171-2008)

Eisen O. (2008) Inference of velocity pattern from isochronous layers in firn, using an inverse method. J. Glaciol., 54(187), 613-630

EPICA Community Members (2004) Eight glacial cycles from an Antarctic ice core. Nature, 429(6992)

EPICA Community Members (2006) One-to-one coupling of glacial climate variability in Greenland and Antarctica. Nature, 444(7116), 195-198

Flach JD, Partington KC, Ruiz C, Jeansou E and Drinkwater MR (2005) Inversion of the surface properties of ice sheets from satellite microwave data. IEEE Trans. Geosci. Remote Sens., 43(4), 743-752 (doi: 10.1109/TGRS.2005.844287)

Flanner MG and Zender CS (2006) Linking snowpack microphysics and albedo evolution. J. Geophys. Res., 111(D12), D12208 (doi: 10.1029/2005JD006834)

Flin F, Brzoska J-B, Lesaffre B, Coléou C and Pieritz RA (2004) Threedimensional geometric measurements of snow microstructural evolution under isothermal conditions. Ann. Glaciol., 38, 39-44 (doi: 10.3189/172756404781814942)

Freitag J, Wilhelms F and Kipfstuhl S (2004) Microstructuredependent densification of polar firn derived from X-ray microtomography. J. Glaciol., 50(169), 243-250 (doi: 10.3189/ 172756504781830123)

Gallet J-C, Domine F, Zender CS and Picard G (2009) Measurement of the specific surface area of snow using infrared reflectance in an integrating sphere at 1310 and $1550 \mathrm{~nm}$. Cryosphere, 3(2), 167-182 (doi: 10.5194/tc-3-167-2009)

Gallet J-C, Domine F, Arnaud L, Picard G and Savarino J (2011) Vertical profile of the specific surface area and density of the snow at Dome C and on a transect to Dumont d'Urville, Antarctica albedo calculations and comparison to remote sensing products. Cryosphere, 5(3), 631-649 (doi: 10.5194/tc-5-631-2011)

Gay M, Fily M, Genthon C, Frezzotti M, Oerter H and Winther JG (2002) Snow grain-size measurements in Antarctica. J. Glaciol., 48(163), 527-535 (doi: 10.3189/172756502781831016)

Gow AJ (1969) On the rates of growth of grains and crystals in South Polar firn. J. Glaciol., 8(53), 241-252

Gow AJ, Meese D and Bialas R (2004) Accumulation variability, density profiles and crystal growth trends in ITASE firn and ice cores from West Antarctica. Ann. Glaciol., 39, 101-109 (doi: 10.3189/172756404781814690)

Hörhold MW, Albert MR and Freitag J (2009) The impact of accumulation rate on anisotropy and air permeability of polar firn at a high-accumulation site. J. Glaciol., 55(192), 625-630 (doi: 10.3189/002214309789471021)

Hörhold MW, Kipfstuhl S, Wilhelms F, Freitag J and Frenzel A (2011) The densification of layered polar firn. J. Geophys. Res., 116(F1), F01001 (doi: 10.1029/2009JF001630)

Isaksson E, Van den Broeke MR, Winther JG, Karlöf L, Pinglot JF and Gundestrup N (1999) Accumulation and proxy-temperature variability in Dronning Maud Land, Antarctica, determined from shallow firn cores. Ann. Glaciol., 29, 17-22 (doi: 10.3189/ 172756499781821445)

Jacka TH and Li J (1994) The steady-state crystal size of deforming ice. Ann. Glaciol., 20, 13-18
Jacobel R, Welch BC, Steig E and Schneider D (2005) Glaciological and climatic significance of Hercules Dome, Antarctica: an optimal site for deep ice core drilling. J. Geophys. Res., 110(F1), F01015 (doi: 10.1029/2004JF000188)

Jordan R (1991) A one-dimensional temperature model for a snow cover: technical documentation for SNTHERM.89. CRREL Spec. Rep. 91-16

Kaempfer TU and Schneebeli M (2007) Observation of isothermal metamorphism of new snow and interpretation as a sintering process. J. Geophys. Res., 112(D24), D24101 (doi: 10.1029/ 2007JD009047)

Lacroix P, Dechambre M, Legrésy B, Blarel F and Rémy F (2008) On the use of the dual-frequency ENVISAT altimeter to determine snowpack properties of the Antarctic ice sheet. Remote Sens. Environ., 112(4), 1712-1729 (doi: 10.1016/j.rse.2007.08.022)

Land Processes Distributed Active Archive Center (LP DAAC) (2009) MODIS/Aqua Land Surface Temperature/Emissivity 8-Day L3 Global $1 \mathrm{~km}$. NASA Land Processes Distributed Active Archive Center, Sioux Falls, SD. Digital media

Legrésy B and Rémy F (1998) Using the temporal variability of satellite radar altimetric observations to map surface properties of the Antarctic ice sheet. J. Glaciol., 44(147), 197-206

Maeno N and Ebinuma T (1983) Pressure sintering of ice and its implication to the densification of snow at polar glaciers and ice sheets. J. Phys. Chem., 87(21), 4103-4110

Munk J, Jezek KC, Forster RR and Gogineni SP (2003) An accumulation map for the Greenland dry-snow facies derived from spaceborne radar. J. Geophys. Res., 108(D9), 4280 (doi: 10.1029/2002JD002481)

Nishimura H and Maeno N (1985) Studies on structures and physical properties of snow on Mizuho Plateau, Antarctica. Ann. Glaciol., 6, 105-107

Paterson WSB (1994) The physics of glaciers, 3rd edn. Elsevier, Oxford

Rott H, Sturm K and Miller H (1993) Active and passive microwave signatures of Antarctic firn by means of field measurements and satellite data. Ann. Glaciol., 17, 337-343

Schneebeli M and Sokratov SA (2004) Tomography of temperature gradient metamorphism of snow and associated changes in heat conductivity. Hydrol. Process., 18(18), 3655-3665

Schwager M (2000) Eisbohrkernuntersuungen zür räumlichen und zeitlichen Variabilität von Temperature und Niederschlagsrate im Spätholozän in Mordgrönland. Ber. Polarforsch. 362

Shiraiwa T, Shoji H, Saito T, Yokoyama K and Watanabe O (1996) Structure and dielectric properties of surface snow along the traverse route from coast to Dome Fuji Station, Queen Maud Land, Antarctica. Proc. NIPR Symp. Polar Meteorol. Glaciol., 10, 1-12.

Sturm M, Holmgren J, König M and Morris K (1997) The thermal conductivity of seasonal snow. J. Glaciol., 43(143), 26-41

Taylor LD (1971) Glaciological studies on the South Pole traverse, 1962-1963. In Crary AP ed. Antarctic snow and ice studies II. American Geophysical Union, Washington, DC, 209-224 (Antarctic Research Series 16)

West RD (1994) Microwave emission from polar firn. (PhD thesis, University of Washington)

Wilhelms F (1996) Leitfähigkeits- und Dichtemessung an Eisbohrkernen. Ber. Polarforsch/Rep. Pol. Res. 191

Wilhelms F (2000) Messung dielektrischer Eigenschaften polarer Eiskerne. Ber. Polar-Meeresforsch./Rep. Pol. Mar. Res. 367

Zwally HJ and Li J (2002) Seasonal and interannual variations of firn densification and ice-sheet surface elevation at Greenland summit. J. Glaciol., 48(161), 199-207 (doi: 10.3189/ 172756502781831403) 